\title{
Use of ferumoxides for stem cell labeling
}

Aim: Although numerous clinical trials have shown promising results with regards to the cardiac regenerative capacity of different types of stem cells, there remains virtually no evidence of the fate of stem cells in these human studies, primarily owing to safety concerns associated with the use of celllabeling strategies. Methods: In this study, we utilized two cell types that are used extensively in cardiac regeneration studies, namely bone marrow-derived human mononuclear cells and C2C12 skeletal myoblasts. The US FDA-approved compounds feridex (ferumoxide) and protamine sulfate (as a transfection agent) were used in combination for cellular labeling. We assessed the effect of this cell labeling strategy on cellular viability, proliferation and differentiation both in vitro and in vivo. Results: The ferumoxideprotamine sulfate combination had no effect on cellular viability, proliferation or differentiation. We show that the labeled human mononuclear cells were easily identified within the rat myocardium 1 month following injection into the myocardium. These human cells expressed human-specific cardiac troponin I, whereas the neighboring rat myocardium did not. Furthermore, we demonstrated that this labeling strategy can be used with high accuracy for magnetic separation of the labeled cells based on the intracellular ferumoxide particles. Conclusions: The ferumoxide-protamine sulfate combination can be used safely and effectively to enhance the detection and isolation of cardiogenic stem cell populations.

KEYWORDS: cardiomyocytes, cell-transfer therapies, ferumoxides, heart, human stem cells, stem cells

Adult tissues have a variable regenerative capacity due to the presence of resident or nonresident stem/progenitor cell populations. For example, lineages such as skin, skeletal muscle, bone marrow and liver have a remarkable regenerative capacity. By contrast, the brain and the heart are more limited in their regenerative potential. Recent studies suggest that resident and extracardiac stem cell populations contribute to limited myocardial repair and regeneration, although numerous animal studies have yielded contradictory results fueling considerable controversy for this field [1-9]. Similarly, clinical trials have demonstrated contradictory results with regards to improvement of cardiac function following cell-based therapies [10-14]. A challenge for this field is the ability to define the fate of stem cell populations in vivo following differentiation (i.e., detection of the products of stem cells after they acquire a cardiac fate). While this is a relatively straight forward task in vitro, it is exceedingly difficult to fully interrogate the fate of stem cells in vivo. Technical difficulties of identifying and isolating stem cells following in vivo delivery range from loss or dispersion (i.e., bystander labeling) of cell tags to the inability to exclude cell fusion or toxic effects of cellular labels [15]. These difficulties are compounded in the clinical-research scenario where the safety profile of cell-labeling strategies is a major deterrent for the use of most of the commercially available labeling compounds. In the present study, we characterized the use of US FDAapproved compounds for the labeling of stem cell populations.

Ferumoxides is an FDA-approved iron oxidebased MRI contrast agent that is primarily used to enhance hepatic imaging (ferumoxides reduce the intensity of normal liver on $\mathrm{T}_{2}$-weighted imaging to improve MRI contrast). Recently, the evidence of several reports have indicated that ferumoxides can be used effectively to track and identify stem cell populations [16]. The heparin antidote protamine sulfate has been demonstrated to enhance the labeling efficiency of ferumoxides [17-19], and displayed a higher transfection efficiency compared with poly-L-lysine [20]. We utilized this strategy for labeling of stem cell populations that are currently being used in clinical trials for cardiac repair. We demonstrate that the ferumoxidesprotamine sulfate combination is a safe and effective method for labeling of various stem cell populations. It can be detected within stem cells in vivo for up to 1 month following delivery, and it does not deleteriously affect cardiac
Hesham Sadek ${ }^{1}$

Shuaib Latif ${ }^{1}$,

Robert Collins ${ }^{1}$,

Mary G Garry ${ }^{1}$

\& Daniel J Garry $y^{1,2,3+}$

${ }^{+}$Author for correspondence:

Lillehei Heart Institute,

420 Delaware Street SE,

MMC508, University of

Minnesota, Minneapolis,

MN 55455, USA

Tel.: +1 6126260154

Fax: +16126264411

E-mail: garry@umn.edu

${ }^{1}$ Department of Internal

Medicine, University of Texas

Southwestern Medical Center,

TX, USA

${ }^{2}$ Department of Molecular

Biology, University of Texas

Southwestern Medical Center,

TX, USA

${ }^{3}$ Donald W Reynolds

Cardiovascular Clinical

Research Center at UT

Southwestern Medical Center, TX, USA

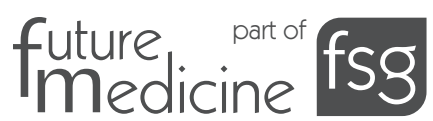


function when used to label cardiomyocytes. Moreover, we describe a novel method for magnetic cell isolation based on intracellular labeling with ferumoxides. This cell isolation technique displayed very high selectivity and can be potentially used to enhance our understanding of the fate of stem cells in vivo.

\section{Methods}

\section{Cell culture \& labeling protocol}

C2C12 skeletal myoblasts (P8-10) were cultured under standard growth and differentiation conditions. The culture media consisted of Dulbecco's Modified Eagle's Medium (Mediatech Inc., VA, USA), 10\% Hyclone fetal bovine serum (Hyclone, UT, USA), Penicillin and streptomycin (10,000 units/ml penicillin and $10 \mathrm{mg} /$ $\mathrm{ml}$ streptomycin [Sigma Aldrich, USA]), L-glutamate (Sigma Aldrich) and ferumoxides (Feridex, Berlex Laboratories, USA).

Human apheresis blood was obtained from healthy donors following conventional granulocyte colony-stimulation factor mobilization. This was followed by isolation of the mononuclear cell fraction by ficoll gradient centrifugation. The human mononuclear cells were cultured in $X$-vivo 20 culture media (Cambrex Bioscience, MD, USA) at $2 \times 10^{6} / \mathrm{ml}$.

\section{Ferumoxides-protamine sulfate labeling}

Following culture for $12 \mathrm{~h}$ under standard culture conditons, the media was changed and the cells were divided into control and ferumoxides-protamine sulfate-labeled groups. The ferumoxides-protamine sulfate mixture was prepared as previously described $[17,18]$ by mixing protamine sulfate and ferumoxides for $10 \mathrm{~min}$, followed by the addition of the mixture to culture media (final concentration $30 \mu \mathrm{g} / \mathrm{ml}$ ferumoxides and $5 \mu \mathrm{g} / \mathrm{ml}$ protamine sulfate). Following labeling for $12 \mathrm{~h}$, the ferumoxides-protamine sulfate-containing media was removed and the cells were washed twice with phosphate-buffered saline (PBS) prior to adding normal media.

In order to determine the feasibility of using the ferumoxides-protamine sulfate combination in stem cell labeling, we undertook kinetics studies to define the time-to-loss of labeling in relation to cellular doubling. Both labeled and nonlabeled $\mathrm{C} 2 \mathrm{C} 12$ cells were allowed to divide. The cells were trypsinized at $90 \%$ confluency, washed and 1000 cells were stained on a glass slide using Prussian blue (equal parts of $20 \% \mathrm{HCl}$ and $4 \%$ potassium ferrocyanide for $10 \mathrm{~min}$ ). The percentage of labeled cells was determined at each time point. The loss of label as a function of cellular doubling was plotted as an index of labeling kinetics. For viability studies, C2C12 cells were trypsinized (0.25\% Trypsin EDTA; Mediatech Inc.) following exposure to ferumoxides-protamine sulfate for $12 \mathrm{~h}$ and evaluated for trypan blue uptake (live cells stain negative for trypan blue). For proliferation studies, C2C12 cells were allowed to grow to $90 \%$ confluency. This was followed by trypsinization and re-plating at $1 \times 10^{4}$ cells $/ \mathrm{ml}$ for 1 week. No cells were discarded in this process. The total number of cells after 1 week was determined in both the ferumoxides-protamine sulfate-treated and control groups.

\section{Magnetic cell sorting of ferumoxides-protamine sulfate-treated cells}

We utilized the MACS magnetic cell sorting magnet and column (Miltenyi Biotech, Germany) to isolate iron-labeled cells. Human mononuclear cells were utilized in these experiments because of their small size, which facilitates their elution through the column. Following staining with ferumoxides-protamine sulfate combination, labeled and nonlabeled cells were mixed thoroughly. The mixture of labeled and nonlabeled cells was applied to the column following its insertion into the magnet. The column was then washed several times and the effluent was collected. The column was then removed from the magnet and washed again. The effluent was again collected. Both effluents were collected on a glass slide (Cytospin 2, Pegasus Scientific, MD, USA). The cells were then stained with Prussian blue staining protocol. The number of iron-positive and -negative cells was determined in both the first and second effluents.

\section{- Prussian blue staining for detection of intracellular iron}

Following labeling, the cells were washed with PBS, fixed with $4 \%$ paraformaldehyde for 10 min and washed with PBS. Prussian blue staining was performed by the addition of equal volumes of $4 \%$ potassium ferrocyanide $\left(\mathrm{K}_{4} \mathrm{Fe}[\mathrm{CN}]_{6}\right)$ (Sigma Aldrich) in $20 \% \mathrm{HCl}$ for $10 \mathrm{~min}$. The potassium ferrocyanide/ $\mathrm{HCl}$ solution was removed and the cells were counterstained with nuclear fast red for $5 \mathrm{~min}$. The iron-positive cells were identified by intracytoplasmic basophilic granules. 
In vivo myocardial staining of cardiomyocytes with ferumoxides

In vivo staining of cardiomyocytes with the ferumoxides-protamine sulfate combination was carried out by direct intramyocardial injection. The surgical procedure was performed as previously described by our laboratory [21]. Following lateral thoracotomy and pericardiectomy, $1 \mathrm{ml}$ of ferumoxides-protamine sulfate combination was delivered into the myocardium circumferentially by multiple injections $(100 \mu \mathrm{l} /$ injection) using a 30 -gauge needle. Echocardiographic evaluation was carried out before the surgery and then at 3,5 and 7 days postoperatively. Fractional shortening $(\mathrm{FS})$ was determined by the following equation: $\mathrm{FS}=([$ end diastolic dimension (EDD) - end systolic dimension]/EDD) - 100. Four animals were used for each group. The animals were sacrificed at 7 days and the hearts were perfusion fixed using 4\% PFA followed by paraffin embedding. The sections ( $4 \mu \mathrm{m}$ in thickness) were evaluated using the Prussian blue staining protocol for the presence of iron staining.

\section{- Intramyocardial delivery of labeled human mononuclear cells}

To determine the utility of ferumoxides-protamine sulfate labeling for in vivo detection of labeled stem cells, we designed a protocol in which labeled human mononuclear cells were injected into the myocardium of athymic nude rats to minimize rejection. The surgical procedure was carried out as reported previously by our laboratory [21]. Human mononuclear cells were isolated and

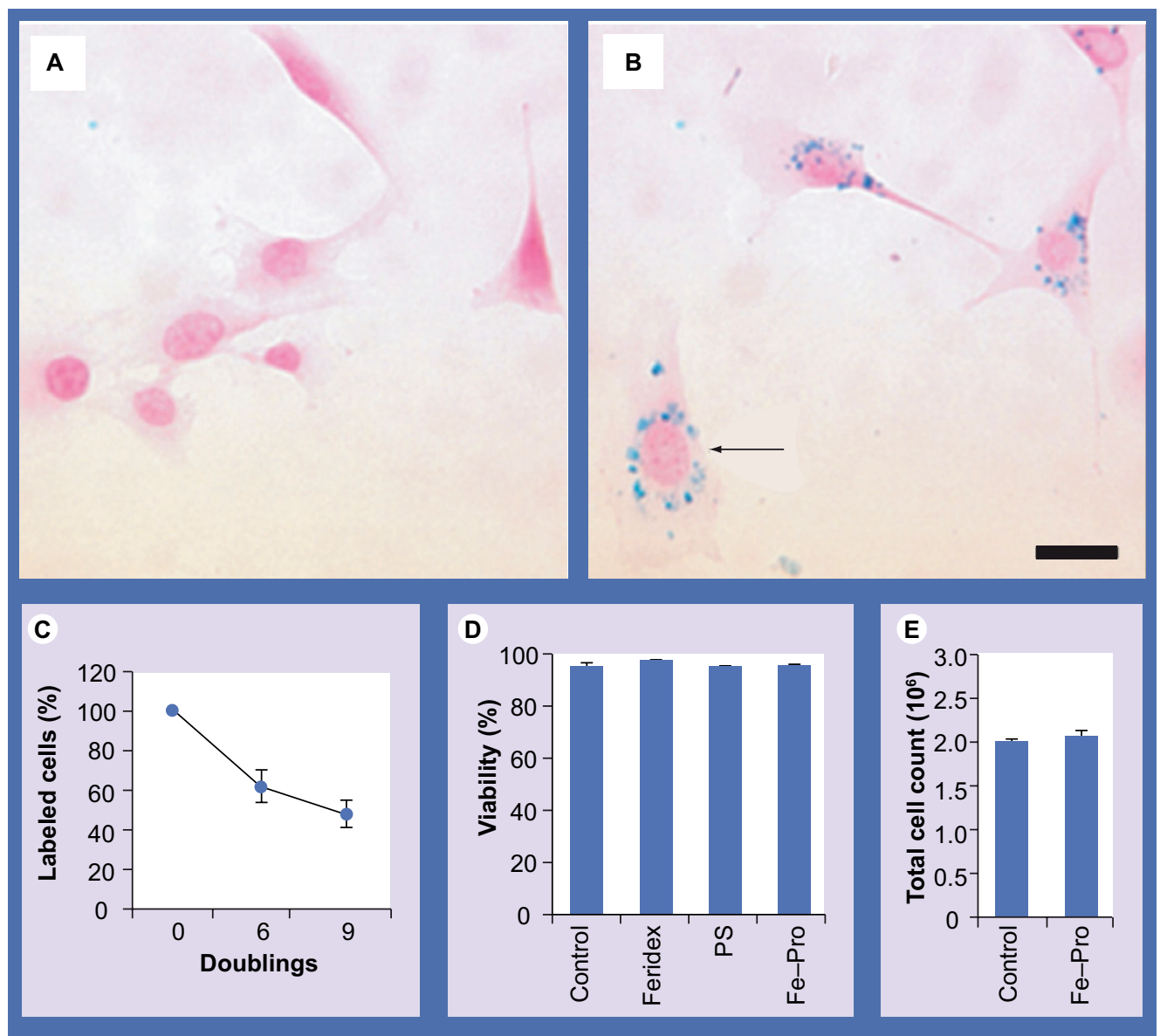

Figure 1. Ferumoxides-protamine sulfate labeling of C2C12 cells. (A) Normal, proliferating, nonlabeled C2C12 cells stained with Prussian blue. (B) Feromoxides-protamine sulfate-labeled C2C12 cells with cytoplasmic basophilic iron particles (arrowhead) following Prussian blue staining. (C) Intracellular iron particles are detected in approximately $50 \%$ of the cells after nine cellular doublings. (D) Viability of control (nonlabeled) C2C12 cells compared with cells labeled with ferumoxides alone, protamine sulfate alone or ferumoxides-protamine sulfate combination ( $n=3$ each). Note that none of the labeling conditions adversely affected cellular viability (data presented as mean \pm standard error of the mean [SEM]). (E) Proliferation of nonlabeled and ferumoxides-protamine sulfate-labeled C2C12 cells (total number of cells following nine cellular doublings). Note that the labeling had no effect on cellular proliferation (data are mean \pm SEM; $n=3$ each). Scale bar: $20 \mu m$. Fe-Pro: Feromoxides-protamine sulfate; PS: Protamine sulfate. 


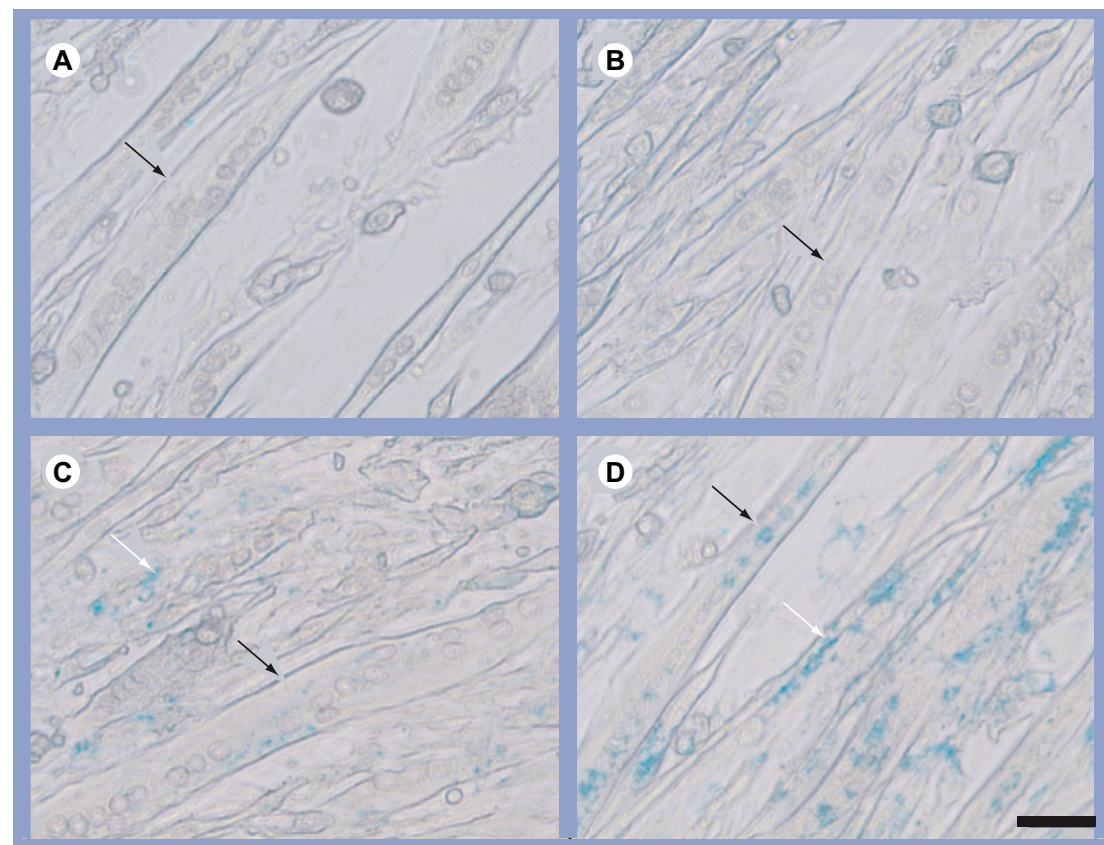

Figure 2. Ferumoxides-protamine sulfate combination does not effect $\mathrm{C} 2 \mathrm{C} 12$ differentiation. Labeled and nonlabeled C2C12 cells were allowed to grow to confluency and then grown in low serum for differentiation to form multinucleated myotubes in all studied groups. (A) Nonlabeled cells under standard conditions form multinucleated myotubes (black arrowhead marks myotubes). (B) Protamine sulfate only labeled C2C12 cells form multinucleated myotubes (arrowhead marks myotubes). (C) Ferumoxides only labeled cells form multinucleated myotubes (white arrowhead marks blue iron particles and black arrowhead marks multinucleated myotubes). (D) Ferumoxides-protamine sulfate-labeled cells reveal normal myotube formation (black arrowhead) and extensive numbers of iron particles (blue; white arrowhead). These data demonstrate that ferumoxides-protamine sulfate labeling does not affect cellular differentiation. Scale bar: $20 \mu \mathrm{m}$.

labeled as described earlier. The cells were then washed, counted and delivered into the myocardium following lateral thoracotomy $\left(90 \times 10^{4}\right.$ cells in a total of $45 \mu \mathrm{l}$ per rat divided over three injections of $15 \mu$ l each). A control group received the same volume of ferumoxide only without cells. Three animals were used in each group. No injury was carried out in these studies; instead the labeled cells were injected directly into the myocardium circumferentially around the left-ventricular anterior wall. This was followed by chest closure and extubation of the animals. The animals were sacrificed 1 month following cell delivery. The hearts underwent perfusion fixation with 4\% PFA and paraffin embedding. The paraffin sections $(5-\mu \mathrm{m}$ thick sections) were evaluated for the presence of Prussian blue-positive cells and immunohistochemical expression of cardiac-specific proteins.

\section{- Immunohistochemical evaluation of human cells}

To further characterize the differentiation potential of the human mononuclear cells, a humanspecific cardiac troponin I antibody (does not recognize rat troponin) was utilized. Moreover, in order to rule out fusion as a mechanism of cardiac differentiation of the human cells, and to identify potential inadvertent labeling of rat cells by ferumoxides, we utilized a rat-specific $\alpha$-actinin antibody (does not crossreact with human cells).

Paraffin-embedded sections were de-waxed by $3 \times 10$ min exposures to xylene, and rehydrated in a graded series of ethanol solutions (100, 95 and $70 \%$ ) for $10 \mathrm{~min}$ each, followed by water for $5 \mathrm{~min}$. The sections first underwent Prussian blue staining. The slides were then rinsed and incubated with $0.1 \%$ pronase (Sigma Aldrich) solution for $10 \mathrm{~min}$ at room temperature. Following blocking for specific secondary antibody, the sections were incubated with either a human-specific troponin I primary antibody (human troponin I antibody T8665-16C, USBiological, USA) at 1:200 dilution for $1 \mathrm{~h}$ at room temperature, or with a rat-specific $\alpha$-actinin antibody ( $\alpha$-actinin clone [EA-53 Sigma]) at 1:200 dilution for $1 \mathrm{~h}$ at room temperature. Rhodamine-linked goat antimouse serum was used as a secondary antibody for the human-specific troponin I antibody, while FITC-linked goat antimouse serum was used as secondary antibody for rat-specific actinin antibody.

\section{Results}

\section{Ferumoxides-protamine sulfate efficiently labels cell populations}

The ability of stem cells to proliferate or exit from the cell cycle and differentiate into a specific lineage are essential characteristics for cell-based therapies. Therefore, the utility of a stem cell-labeling strategy is dependent on the absence of any deleterious effect of the cellular labeling protocol on proliferation and differentiation, as well as the ability for the cells to retain the label following numerous cellular doublings. We initially utilized the $\mathrm{C} 2 \mathrm{C} 12$ myogenic cell line in our labeling studies. The $\mathrm{C} 2 \mathrm{C} 12$ cells were easily labeled and identified by intracytoplasmic iron granules (Figure 1B). These granules were detected in $48.12 \%$ of cells after nine cellular doublings (standard error [SE]: 3.26) (Figure 1C). These findings suggest that this labeling technique can be effectively used to label rapidly dividing stem cells, and this technique retains the ability to identify labeled cells even after a significant number of doublings.

\section{- Ferumoxides-protamine sulfate combination has no effect on cellular viability, proliferation or differentiation}

To further characterize the safety profile of ferumoxides-protamine sulfate combination, 
we undertook a series of experiments in which the effect of cellular labeling on viability, proliferation and differentiation of $\mathrm{C} 2 \mathrm{C} 12$ cells was determined. Our studies indicate that ferumoxides-protamine sulfate labeling has no effect on cellular viability as determined by Trypan blue exclusion staining (control viability: 94.8\%, SE: $1.8 \%$; ferumoxides viability: $97.4 \%$, SE: $0.9 \%$, $\mathrm{p}=\mathrm{NS}$ compared with control; protamine sulfate viability: $94.8 \%$, SE: $0.46 \%, \mathrm{p}=\mathrm{NS}$ compared with control; ferumoxides-protamine sulfate combination viability: $95.1 \%$, SE: $0.73 \%, p=N S$ compared with control) (Figure 1D). Moreover, the ferumoxides-protamine sulfate labeling had no effect on cellular proliferation after nine cellular doublings (Figure 1E). Finally, the labeled C2C12 cells, when allowed to grow to confluency (which is a stimulus for differentiation into myotubes) and cultured in low serum, displayed no change in their differentiation capacity when compared with unlabeled $\mathrm{C} 2 \mathrm{C} 12$ cells, as determined by normal myotube formation in all four groups

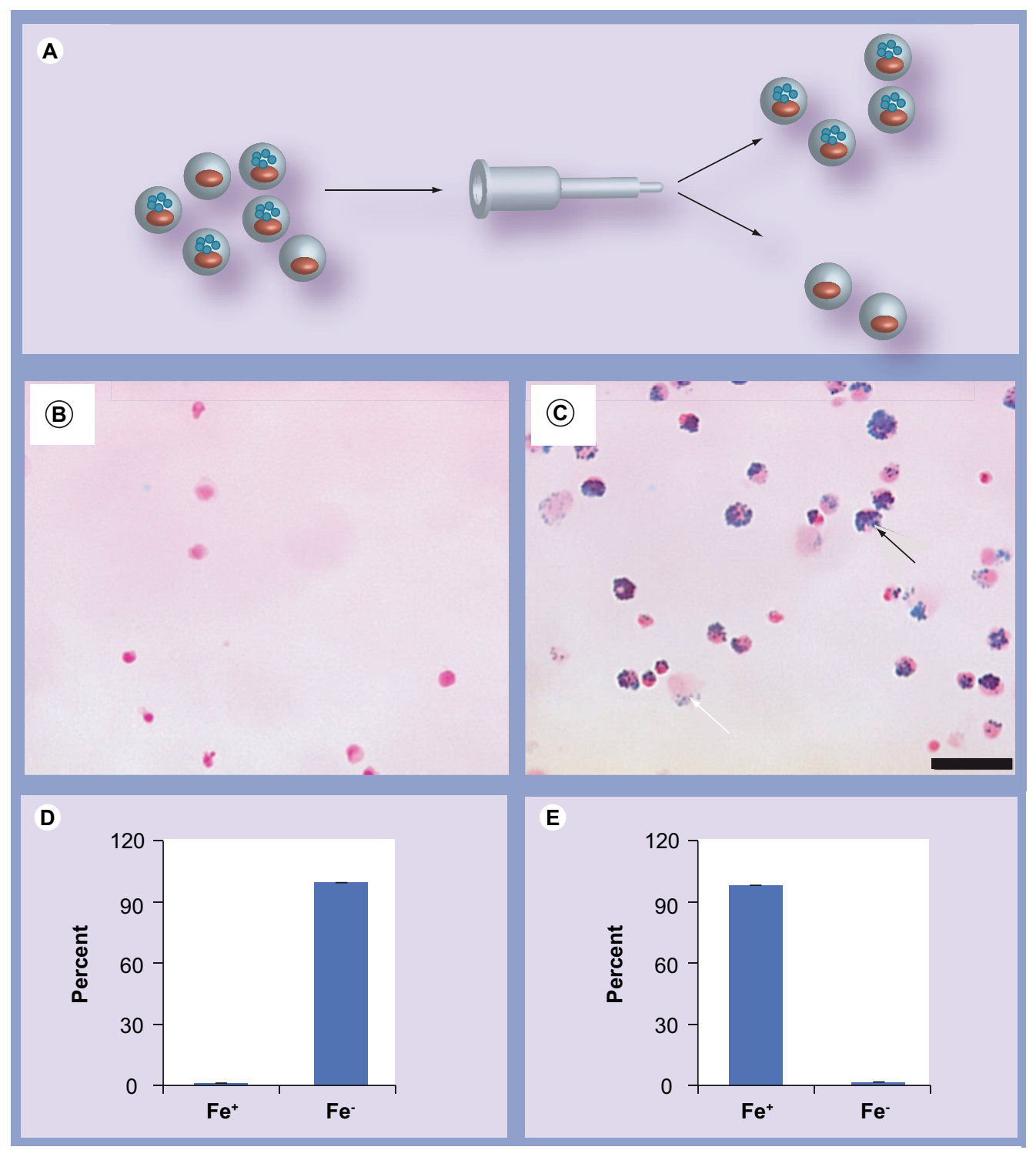

Figure 3. Magnetic cell sorting of ferumoxides-protamine sulfate-labeled human mononuclear cells. Intracellular iron oxide particles enabled magnetic cell sorting of labeled human mononuclear cells. (A) Schematic illustration of the magnetic cell sorting of a mixture of labeled and nonlabeled cells. (B) Nonlabeled cells do not bind to the magnet and are readily eluted. (C) Labeled cells bind to the magnet and are eluted only after removal of the column from the magnet (white arrowhead marks lightly stained cells and black arrowhead marks intensely stained cells). (D) Quantitative analysis of data presented in (B) reveal a high capacity for excluding the nonlabeled cells (negative selection) $98.5 \%$ ( $n=3$ samples). (E) Quantitative analysis of data presented in (C) reveal a high capacity for accurately selecting labeled cells (positive selection) 99.3\% ( $n=3$ each). Scale bar: $30 \mu \mathrm{m}$. 


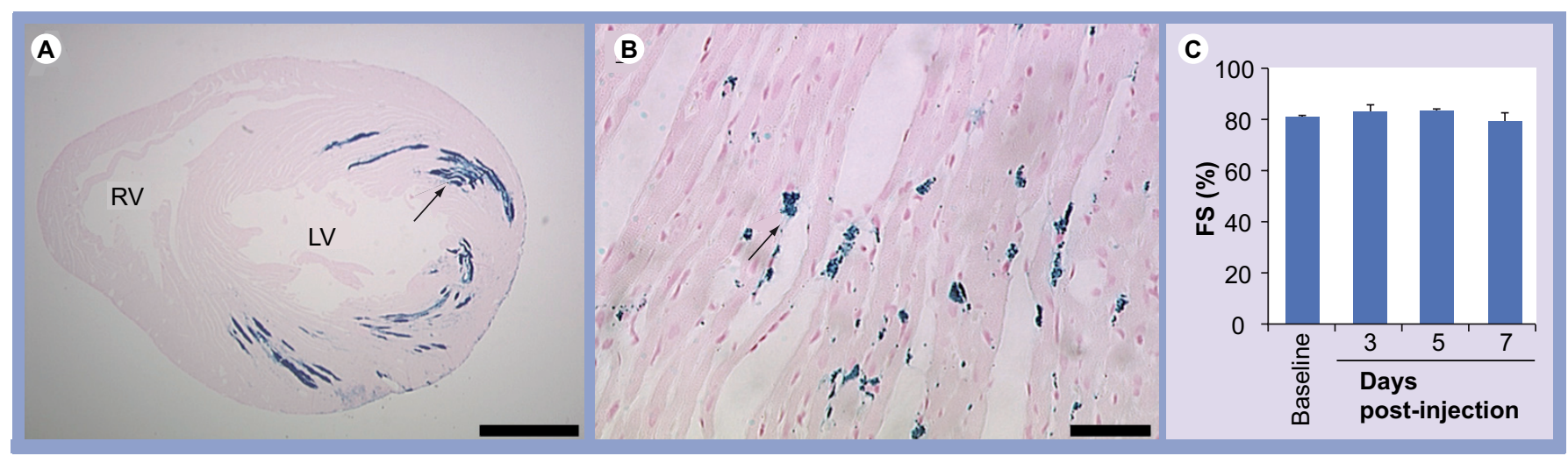

Figure 4. In vivo labeling of cardiomyocytes with the ferumoxides-protamine sulfate combination. (A) Ferumoxides-labeled left ventricle (7 days post-ferumoxides-protamine sulfate injection) stained with Prussian blue. Note the circumferential labeling of the myocardium. Scale bar: $1000 \mu \mathrm{m}$. (B) Higher magnification showing intracellular iron oxide particles (arrowhead). Scale bar: $40 \mu \mathrm{m}$ (C) Left ventricular function using echocardiography (i.e., FS) prior to injection of ferumoxides-protamine sulfate and at 1, 3, 5 and 7 days postinjection into the myocardium (mean \pm standard error of the mean; $n=3$ each). Note the preserved FS at all time points.

FS: Fractional shortening.

(Figure 2A-D). These results provide further support for the use of ferumoxides-protamine sulfate combination as a stem cell-labeling technique.

Ferumoxides-protamine sulfatelabeled cells can be isolated using magnetic cell sorting

We utilized a novel strategy for the isolation of cells that included magnetic cell sorting of the intracellular ferumoxides-labeled cells (Figure 3A). Following ferumoxides labeling, standard magnetic cell-sorting protocol utilizing the MACS system resulted in very high selectivity for isolating the labeled cells. After addition of a mixture of labeled and no labeled cells to the magnet, only the labeled cells remained attached to the magnet while the unlabeled cells readily eluted (Figure 3B). Following removal of the column from the magnet, the ferumoxides-containing cells readily eluted (Figure 3C). The effluents were then plated on a slide and stained with the Prussian blue staining protocol. This method of cell isolation based on intracellular ferumoxides labeling displayed very high selectivity for ferumoxide-containing cells with a positive selection of $98.5 \%$ (SE: $0.3 \% ; \mathrm{p}<0.001)$ and negative selection of $99.3 \%$ (SE: 0.4\%; $\mathrm{p}<0.001$ ) (Figure 3D \& E).

\section{In vivo cardiomyocyte labeling with ferumoxides-protamine sulfate combination does not adversely affect left-ventricular function}

We assessed the effect of in vivo labeling of leftventricular cardiomyocytes with ferumoxides to determine whether the labeling strategy interferes with normal cardiomyocyte contractile function. Left-ventricular function was defined under baseline conditions and following intramyocardial injection of the ferumoxides-protamine sulfate combination at 3, 5 and 7 days. The FS was unchanged at all time points ranging from 79 to 83\% (SE: 0.79-2.64; $\mathrm{p}=\mathrm{NS}$ ) (Figure 4C). These results indicate that in vivo labeling of cardiomyocytes with ferumoxides has no effect on FS, despite extensive circumferential labeling of the left ventricle at 1 week postlabeling (FIGURE 4A \& B).

\section{Ferumoxides-labeled human mononuclear cells acquire a cardiac fate}

We assessed the cardiac differentiation potential of ferumoxides-labeled human mononuclear cells following their delivery into the rat myocardium. Athymic nude rats were utilized to minimize rejection. As outlined earlier, the human mononuclear cells were labeled with ferumoxides and delivered into the uninjured athymic nude rat (a total of $900 \mathrm{~K}$ cells delivered via three separate injections). The animals recovered and were maintained for a 1-month period until they were sacrificed. The hearts were perfusion fixed, washed, embedded and sectioned 1 month following delivery. Serial sectioning of the rat hearts followed by Prussian blue staining to detect the human mononuclear cells revealed a needle track with numerous ironpositive mononuclear cells (Figure 5A).

To further characterize the differentiation potential of these human mononuclear cells, a human-specific cardiac troponin I antibody that does not recognize rat troponin was utilized. Moreover, in order to rule out fusion as a mechanism of cardiac differentiation of the human cells, and to identify potential inadvertent labeling of rat cells by ferumoxides, we utilized a rat-specific $\alpha$-actinin antibody that does not cross react with human cells. 
These ferumoxides-labeled human mononuclear cells exclusively expressed human cardiac troponin I, as indicated by intense fluorescence of the ferumoxides-labeled cells in the needle track compared with the lack of staining in the neighboring rat myocardium (FIGUre 5B \& C). Further proof of cardiac differentiation of the human mononuclear cells is offered by exclusive staining of the rat myocardium with the rat-specific $\alpha$-actinin antibody while the ferumoxides-labeled human cells did not stain with the rat-specific antibody (FIgure 5D \& E). This not only provides proof that there is minimal or no fusion of the human mononuclear cells with the rat cells, but also that the ferumoxides remain within the human cells even 1 month following delivery into the rat myocardium.

\section{Discussion}

Intense interest has recently focused on regenerative medicine. There are numerous promising reports that suggest varying degrees of regenerative capacity of different types of stem cells. Recent studies challenge the notion that the adult heart is incapable of regeneration and these studies have proposed that resident and extracardiac stem cells participate in this process. Perhaps the most robust and reproducible method for the specification and induction of cardiac differentiation is the stimulation of stem cells through the exposure to a cardiac microenvironment (either in vitro by co-culture with cardiomyocytes [22-24] or in vivo by delivery into the myocardium $[2,4,25,26])$. These studies further support that an enhanced understanding of the factors that influence the improvement in cardiac function associated with cell-based therapy is unclear. This is perhaps due to the complexity of the in vivo system and the lack of a comprehensive understanding of the factors (or anatomical associations) that influence cellular proliferation and cardiac differentiation. These factors may include cell-to-cell contact [23], extracellular release of cardiogenic factors [27], electrical stimulation $[28,29]$, pressure stimulation [30] or cellular fusion [1]. Therefore, a mechanistic and methodological approach to the cardiogenic differentiation potential of stem cells is required. Cell-based therapies require the ability to identify and track the fate of the delivered cell population at different stages of differentiation. While genetic labeling of cells can be achieved with relative ease in animal studies, these transgenic strategies have little utility in clinical trials. Furthermore, the use of intercalating agents (5-bromo-2'-deoxyuridine [BrdU], propidium iodide and 4'-6-diamidino2-phenylindole [DAPI]) or the delivery of viral vectors that express a fluorescent reporter lack the safety profile for use in stem cell-labeling protocols.

Currently, there are numerous ongoing as well as published clinical trials utilizing skeletal myoblasts [31-36] and bone marrow-derived mononuclear cells [37-41] for myocardial regeneration. In the current study, we utilized these two cell types to outline the use of the combination of protamine sulfate as a transfection agent and ferumoxides as an intracellular iron label. This method displays very effective labeling with no adverse effect on cellular viability, proliferation or differentiation. In addition, the ferumoxides-protamine sulfate-labeled human mononuclear cells were easily detected within the rat myocardium 30 days following intramyocardial injection. These cells expressed human-specific cardiac troponin I as compared with the neighboring rat myocardium. This

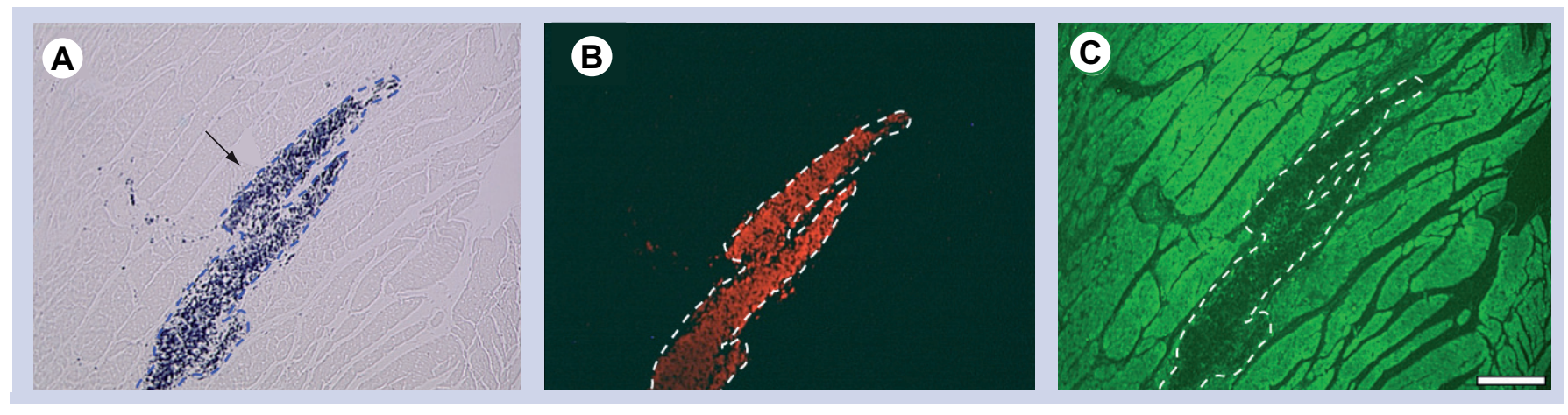

Figure 5. Cardiac differentiation of labeled human mononuclear cells following delivery into the rat myocardium.

Ferumoxides-protamine sulfate-labeled human mononuclear cells were delivered (intramyocardial) into the athymic nude rat. These rodents were sacrificed 30 days following delivery of the labeled human cells. (A) Prussian blue staining illustrates the persistence of ferumoxides (blue; arrowhead) within the human mononuclear cells 1 month following intramyocardial injection. (B) Human specific troponin I immunohistochemical staining reveals the exclusive staining of the human cells while the neighboring rat myocardium remains unstained. (C) Rat-specific $\alpha$-actinin immunohistochemical staining reveals expression of the rat myocardium while the human cells remain unstained. Scale bar: $30 \mu \mathrm{m}$. 
finding suggests that the human bone marrow mononuclear cells are capable of expressing human cardiac proteins within the rat myocardium, and that ferumoxides labeling does not interfere with the differentiation process. These results are complemented by our studies utilizing chemical genetics to promote the cardiac fate of human bone marrow mononuclear cells [42]. Future studies will further extend these results and will utilize an analysis of in vivo survival of the human stem cell populations using reporter gene expression (i.e., green-fluorescent protein or luciferase) and optical bioluminescence, qRT-PCR of human-specific gene expression or human protein expression using other cardiac-specific antisera.

In order to determine whether ferumoxides labeling effects contractile function in vivo, we labeled rat left-ventricular myocardium with the ferumoxides-protamine sulfate combination and analyzed left-ventricular function (i.e., FS) at three different time points postinjection. Ferumoxides labeling of cardiomyocytes in vivo did not adversely affect contractile function of the left ventricle, despite extensive histological evidence of labeling by Prussian blue staining. Collectively, these findings indicate that ferumoxides-protamine sulfate combination has no effect on cellular viability, proliferation, differentiation or contractile function.

A major dilemma of stem cell research is the inability to fully interrogate stem cells following their differentiation in vivo. This is of particular importance when using autologous stem cells, where even fluorescent in situ hybridization cannot be utilized. It is well recognized that the conventional method for the identification of stem cells is the expression of cell-surface proteins that serve as markers. These surface markers are lost or altered once the stem cell differentiates into a certain lineage. Therefore, intracellular labels that are not modified by the differentiation process are crucial in identification of stem cells following their differentiation in vivo. As mentioned earlier, genetic labels are of no value in clinical studies owing to obvious safety issues. In this study, we characterized a novel use of a safe and effective cell-labeling technique that enables magnetic cell sorting of the labeled cells. This novel method of magnetic cell sorting can be utilized for isolation of stem cells after their differentiation and can facilitate characterization of these cells by immunohistochemical or molecular techniques.

In conclusion, ferumoxides and protamine sulfate, two FDA-approved compounds, can be combined to safely and effectively label two cell types that are widely used in cardiac regeneration studies, namely mononuclear cells and skeletal myoblasts. Our data indicate that this cell-labeling strategy does not adversely affect important parameters of these stem cells such as cellular proliferation and differentiation, as indicated by the multinucleated myotube formation of $\mathrm{C} 2 \mathrm{C} 12$ cells in vitro and the expression of human troponin I by the human mononuclear cells in vivo. Moreover, labeling of adult cardiomyocytes in vivo did not adversely affect their contractile performance. Finally, we characterized a novel method for magnetic cell sorting based on intracellular ferumoxides labeling that will facilitate the identification and characterization of stem cells in their in vivo environment.

\section{Financial \& competing interests disclosure}

This research was supported by the American Heart Association (H Sadek and DJ Garry). DJ Garry is an Established Investigator of the AHA. The authors have no other relevant affliations or financial involvement with any organization or entity with a financial interest in or financial conflict with the subject matter or materials discussed in the manuscript apart from those disclosed.

No writing assistance was utilized in the production of this manuscript.

- We described an effective method for stem cell labeling using ferumoxides and protamince sulfate that can facilitate the in vivo identification and isolation of stem cells.

- Human mononuclear cells and mouse C2C12 skeletal myoblasts were used for labeling studies.

- The effect of ferumoxides and protamine sulfate on cellular viability and proliferation was determined using standard techniques. Moreover, the effect of in vivo labeling of cardiomyocytes was determined by echocardiographic assessment of left-ventricular function following direct injection of ferumoxide-protamine sulfate combination into the myocardium.

- Finally, human mononuclear cells labeled with the ferumoxides-protamine sulfate combination were directly injected into the myocardium and were identified 1 month later by Prussian blue staining.

- The combination of ferumoxides and protamine sulfate enhanced the labeling of stem cell populations and had no deleterious effects on cellular viability or proliferation. Moreover, this labeling strategy facilitated the in vitro isolation and identification of the labeled cells.

- The combination of ferumoxides and protamine sulfate is an effective method for stem cell labeling that does not interfere with cellular viability, proliferation and the differentiation capacity of stem cells. 


\section{Bibliography}

1 Nygren JM, Jovinge S, Breitbach $M$ et al.: Bone marrow-derived hematopoietic cells generate cardiomyocytes at a low frequency through cell fusion, but not transdifferentiation. Nat. Med. 10, 494-501 (2004).

2 Balsam LB, Wagers AJ, Christensen JL, Kofidis T, Weissman IL, Robbins RC: Haematopoietic stem cells adopt mature haematopoietic fates in ischaemic myocardium. Nature 428, 668-673 (2004).

3 Jackson KA, Majka SM, Wang H et al.: Regeneration of ischemic cardiac muscle and vascular endothelium by adult stem cells. J. Clin. Invest. 107, 1395-1402 (2001).

4 Orlic D, Kajstura J, Chimenti S et al.: Bone marrow cells regenerate infarcted myocardium. Nature 410, 701-705 (2001).

5 Orlic D, Kajstura J, Chimenti S, Bodine DM, Leri A, Anversa P: Transplanted adult bone marrow cells repair myocardial infarcts in mice. Ann. NY Acad. Sci. 938, 221-229; discussion 229-230 (2001).

6 Murry CE, Soonpaa MH, Reinecke $\mathrm{H}$ et al.: Haematopoietic stem cells do not transdifferentiate into cardiac myocytes in myocardial infarcts. Nature 428, 664-668 (2004).

7 Urbanek K, Quaini F, Tasca G et al.: Intense myocyte formation from cardiac stem cells in human cardiac hypertrophy. Proc. Natl Acad. Sci. USA 100, 10440-10445 (2003).

8 Dawn B, Stein AB, Urbanek K et al.: Cardiac stem cells delivered intravascularly traverse the vessel barrier, regenerate infarcted myocardium, and improve cardiac function. Proc. Natl Acad. Sci. USA 102, 3766-3771 (2005).

9 Yeh ET, Zhang S, Wu HD, Korbling M, Willerson JT, Estrov Z: Transdifferentiation of human peripheral blood CD $34^{+}$-enriched cell population into cardiomyocytes, endothelial cells, and smooth muscle cells in vivo. Circulation 108, 2070-2073 (2003).

10 Assmus B, Fischer-Rasokat U, Honold J et al.: Transcoronary transplantation of functionally competent BMCs is associated with a decrease in natriuretic peptide serum levels and improved survival of patients with chronic postinfarction heart failure: results of the TOPCARE-CHD Registry. Circ. Res. 100, 1234-1241 (2007).

11 Schachinger V, Assmus B, Britten MB et al: : Transplantation of progenitor cells and regeneration enhancement in acute myocardial infarction: final one-year results of the TOPCARE-AMI Trial. J. Am. Coll. Cardiol. 44, 1690-1699 (2004).
12 Lunde K, Solheim S, Aakhus S et al.: Intracoronary injection of mononuclear bone marrow cells in acute myocardial infarction. N. Engl. J. Med. 355, 1199-1209 (2006).

13 Schachinger V, Erbs S, Elsasser A et al.: Intracoronary bone marrow-derived progenitor cells in acute myocardial infarction. N. Engl. J. Med. 355, 1210-1221 (2006).

14 Assmus B, Honold J, Schachinger V et al.: Transcoronary transplantation of progenitor cells after myocardial infarction. $N$. Engl. J. Med. 355, 1222-1232 (2006).

15 Beeres SL, Bengel FM, Bartunek J et al: Role of imaging in cardiac stem cell therapy. J. Am. Coll. Cardiol. 49, 1137-1148 (2007).

16 Walczak P, Kedziorek DA, Gilad AA, Barnett BP, Bulte JW: Applicability and limitations of MR tracking of neural stem cells with asymmetric cell division and rapid turnover: the case of the shiverer dysmyelinated mouse brain. Magn. Reson. Med. 58, 261-269 (2007).

17 Arbab AS, Yocum GT, Kalish H et al.: Efficient magnetic cell labeling with protamine sulfate complexed to ferumoxides for cellular MRI. Blood 104, 1217-1223 (2004).

18 Arbab AS, Yocum GT, Rad AM et al. Labeling of cells with ferumoxides-protamine sulfate complexes does not inhibit function or differentiation capacity of hematopoietic or mesenchymal stem cells. NMR Biomed. 18, 553-559 (2005).

19 Anderson SA, Glod J, Arbab AS et al.: Noninvasive MR imaging of magnetically labeled stem cells to directly identify neovasculature in a glioma model. Blood 105 , 420-425 (2005).

20 Arbab AS, Yocum GT, Wilson LB et al.: Comparison of transfection agents in forming complexes with ferumoxides, cell labeling efficiency, and cellular viability. Mol. Imaging 3, 24-32 (2004).

21 Smith SA, Mammen PP, Mitchell JH, Garry MG: Role of the exercise pressor reflex in rats with dilated cardiomyopathy. Circulation 108, 1126-1132 (2003).

22 Hierlihy AM, Seale P, Lobe CG, Rudnicki MA, Megeney LA: The post-natal heart contains a myocardial stem cell population. FEBS Lett. 530, 239-243 (2002).

23 Fukuhara S, Tomita S, Yamashiro S et al: Direct cell-cell interaction of cardiomyocytes is key for bone marrow stromal cells to go into cardiac lineage in vitro. J. Thorac. Cardiovasc. Surg. 125, 1470-1480 (2003).

24 Messina E, De Angelis L, Frati G et al.: Isolation and expansion of adult cardiac stem cells from human and murine heart. Circ. Res. 95, 911-921 (2004).
25 Toma C, Pittenger MF, Cahill KS, Byrne BJ, Kessler PD: Human mesenchymal stem cells differentiate to a cardiomyocyte phenotype in the adult murine heart. Circulation 105, 93-98 (2002).

26 Kawada H, Fujita J, Kinjo K et al.: Nonhematopoietic mesenchymal stem cells can be mobilized and differentiate into cardiomyocytes after myocardial infarction. Blood 104, 3581-3587 (2004).

27 Dell'Era P, Ronca R, Coco L, Nicoli S, Metra M, Presta M: Fibroblast growth factor receptor-1 is essential for in vitro cardiomyocyte development. Circ. Res. 93, 414-420 (2003).

28 Xia Y, McMillin JB, Lewis A et al.: Electrical stimulation of neonatal cardiac myocytes activates the NFAT3 and GATA4 pathways and up-regulates the adenylosuccinate synthetase 1 gene. J. Biol. Chem. 275, 1855-1863 (2000).

29 Xia Y, Buja LM, Scarpulla RC, McMillin JB: Electrical stimulation of neonatal cardiomyocytes results in the sequential activation of nuclear genes governing mitochondrial proliferation and differentiation. Proc. Natl Acad. Sci. USA 94, 11399-11404 (1997).

30 Guo XM, Zhao YS, Chang HX et al.: Creation of engineered cardiac tissue in vitro from mouse embryonic stem cells. Circulation 113, 2229-2237 (2006).

31 Menasche P, Hagege AA, Vilquin JT et al.: Autologous skeletal myoblast transplantation for severe postinfarction left ventricular dysfunction. J. Am. Coll. Cardiol. 41, 1078-1083 (2003).

32 Menasche P, Hagege AA, Scorsin M et al.: Myoblast transplantation for heart failure. Lancet 357 279-280 (2001).

33 Haider H, Tan AC, Aziz S, Chachques JC, Sim EK: Myoblast transplantation for cardiac repair: a clinical perspective. Mol. Ther. 9, 14-23 (2004).

34 Dib N, McCarthy P, Campbell A et al.: Feasibility and safety of autologous myoblast transplantation in patients with ischemic cardiomyopathy. Cell Transplant 14, 11-19 (2005).

35 Herreros J, Prosper F, Perez A et al.: Autologous intramyocardial injection of cultured skeletal muscle-derived stem cells in patients with non-acute myocardial infarction. Eur. Heart J. 24, 2012-2020 (2003).

36 Smits PC, van Geuns RJ, Poldermans D et al.: Catheter-based intramyocardial injection of autologous skeletal myoblasts as a primary treatment of ischemic heart failure: clinical experience with six-month follow-up. J. Am. Coll. Cardiol. 42, 2063-2069 (2003). 
37 Hamano K, Nishida M, Hirata K et al.: Local implantation of autologous bone marrow cells for therapeutic angiogenesis in patients with ischemic heart disease: clinical trial and preliminary results. Jpn Circ. J. 65, 845-847 (2001).

38 Li TS, Hamano K, Hirata K, Kobayashi T, Nishida M: The safety and feasibility of the local implantation of autologous bone marrow cells for ischemic heart disease. J. Card. Surg. 18(Suppl. 2), S69-S75 (2003).
39 Stamm C, Kleine HD, Choi YH et al.: Intramyocardial delivery of $\mathrm{CD} 133^{+}$ bone marrow cells and coronary artery bypass grafting for chronic ischemic heart disease: safety and efficacy studies. J. Thorac. Cardiovasc. Surg. 133, 717-725 (2007).

40 Stamm C, Westphal B, Kleine HD et al:: Autologous bone-marrow stem-cell transplantation for myocardial regeneration. Lancet 361, 45-46 (2003).
41 Stamm C, Kleine HD, Westphal B et al.: $\mathrm{CABG}$ and bone marrow stem cell transplantation after myocardial infarction. Thorac. Cardiovasc. Surg. 52, 152-158 (2004).

42 Sadek H, Hannack B, Choe E et al.: Cardiogenic small molecules that enhance myocardial repair by stem cells. Proc. Natl Acad. Sci. USA 105, 6063-6068 (2008). 